\title{
Dimensions of Quality in Teacher Education: Perception and Practices of Teacher Educators in the Universities of Sindh, Pakistan
}

\author{
Zafarullah Sahito ${ }^{1,2} \&$ Pertti Vaisanen ${ }^{1}$ \\ ${ }^{1}$ School of Applied Educational Science and Teacher Education, Philosophical Faculty, University of Eastern \\ Finland \\ ${ }^{2}$ Sukkur IBA, Sindh, Pakistan, Airport Road, Sukkur, Sindh, Pakistan \\ Correspondence: Zafarullah Sahito, School of Applied Educational Sciences and Teacher Education, Philosophical \\ Faculty, University of Eastern Finland and Sukkur IBA, Sindh, Pakistan, Airport Road, Sukkur, Sindh, Pakistan.
}

Received: October 16, 2017

Accepted: November 8, 2017

Online Published: November 14, 2017

doi:10.5430/ijhe.v6n6p44

URL: https://doi.org/10.5430/ijhe.v6n6p44

\begin{abstract}
This study was conducted to explore the dimensions of quality education in teacher education departments at universities of Sindh province of Pakistan. The qualitative research approach was employed for data collection and then analysed through thematic-narrative analysis technique. The total eight dimensions of quality were found, as two were concerned with pre-sage, four as process and two as product dimensions, known as 3Ps. The findings of this article would be found reliable resource and an addition in to the existing literature of quality education to understand the phenomenon in existing organisational setting of teacher education departments and institutions in Sindh, Pakistan. The radical reforms for educational and economic development can be brought through better understanding of the phenomenon of the quality education, which support the teacher educators, students and the heads to maintain peace and prosperity for humanity in their respective societies through quality teaching-learning process.
\end{abstract}

Keywords: Perception, Practices, Quality education, Thematic-narrative analysis and teacher educators

\section{Introduction}

Education is the foundation, which consists of the key factors for the development and improvement of economic and social conditions of individuals and society (Barro, 1996; Krueger \& Lindhahl, 2001). As the investment in education leads the formation of human capital towards the economic growth (Tilak, 2002) and development, which can be achieved through education and training in order to enhance the skills of human beings to transform them into more valuable human capital, fully loaded with productive knowledge to increase the productivity and earnings (Tilak, 2002). Education is itself a basic need and important ingredient towards the access of equality educational services, which support to fulfill the necessities to improve the quality of life (International Labour Organization [ILO], 1977). It directly effects on the housing, use of water, sanitation, decisions on fertility, family welfare and health (Lleras-Muney, 2005) of all family members to increase the productivity and reduce poverty (Tilak, 2002).

The purpose of this study was to investigate the perception and the practices of TEs about maintaining the QE at their respective departments, institutions and organisation to increase its respect and demand among public. Because the integration of knowledge, skills and attitudes (Van Merrienboer \& Kirschner, 2007) can be done only through good practices known as QE. It depends on the coordination of different constituent qualitative skills and their transfer to daily life and work settings, which have been learned in school or training (Van Merrienboer \& Kirschner, 2007). As it is a need of the time and supporting and beneficial activity for students to be able to transfer the complex cognitive skills to their daily life consisting of the varied set of real world (Van Merrienboer et al., 2002). Because $\mathrm{QE}$ is a unique tool of $21^{\text {st }}$ century to bring radical reforms in education sector and field in order to achieve the economic developmental goals for the easy and quality life of the people through maintaining the security, peace and prosperity among all communities and societies in the global world.

\section{Quality Education (QE)}

The term quality in education possess the complexity and multifaceted nature in its concept. Where, the words efficiency, effectiveness, equity and quality have been used synonymously (Adams, 1993). It provides the consensus on the basic dimensions of quality education to understand the definition and the phenomenon. QE revolves around 
the learners, environments, contents, processes and outcomes (UNICEF, 2000) such as their families and communities to learn well can support learners who are healthy, well nourished, ready to participate (UNESCO, 2005). Environments that are healthy, safe, protective and gender-sensitive could provide adequate resources and facilities for learning and grooming. Content that is reflected in relevant curricula and materials for the acquisition of basic skills and knowledge in the areas of literacy, numeracy and skills for life, gender, health, nutrition, HIV/AIDS prevention and peace. Processes are to train the teachers to use child-centred teaching approaches in well-managed classrooms and schools through skilful assessment to facilitate learning and reduce differences. While outcomes encompass knowledge, skills and attitudes, which are linked to national goals for education and positive participation in society (NAAC, 2007; Thaung, 2008; UNICEF, 2000). This defines education as a complex system, which is embedded in political, cultural and economic contexts, as an interdependent and influenced on each other in order to boost up the discussion of educational quality (Motala, 2001; Pipho, 2000) in global perspective. In contextualized understanding of quality, the key stakeholders hold different views and meanings of educational quality (Motala, 2001; Benoliel, O'Gara \& Miske, 1999), judged by the school system as final goals set for children, community, country and ourselves (Beeby, 1966).

\subsection{Debate on Quality}

The chronological development of quality in different fields was developed sequentially such as quality as an integral element of craftsmanship (pre 1900); quality control by foremen (1900-1920); inspection based quality control (1920-1940); statistical process control (1940-1960); quality assurance / total quality control by the quality department (1960-1980); total quality management [TQM] (1980-1990); and TQM as the culture of continuous improvement and organisation wide quality management (1990- to date) defined well by Sallis (1996). However, its rapid growth and development was started after World War II (Greenwood \& Gaunt, 1994), due to industrialisation, competition, ensurement of the products, conformation of specifications and customers' satisfaction, the debate on quality was started (Sallis, 1996). In 1980's, UK and USA linked quality with the concepts of total quality, primarily was focused on product quality rather than process quality (Wadsworth, Stephens \& Godfrey, 2002). Later, the total quality control (TQC) was implemented in Japan and then Deming, Crosby, Peters and Juran (Greenwood \& Gaunt, 1994) proposed TQM. That is why the responsibility of quality was shifted from the worker to the processes and system known as the quality control followed by inspection, undertaken at the end of the production process in order to detect defective products.

\subsection{Indicators of Quality}

Quality indicators are generic statements that ensure the comprehensive coverage of the most important relevant domains of quality (National Assessment and Accreditation Council [NAAC], 2007), which reflect the important components of teacher education programmes [TEP] (Yackulic \& Noonan, 2001). As indicators perform several roles to describe the current situation; quantify the pre-determined objectives; provide the continuous feedback towards the advancement of the achievement of objectives; and identify the factors to contribute towards the achievement (European Commission, 2001) quantitatively, narratively (subjective) and both combinedly (Chande, 2006). Learner and its engagement, employer satisfaction and competency completion are found the major quality indicators by Australian Quality Training Framework (AQTF, 2007). As Thaung (2008) explored the learners, teachers, content, teaching learning processes, learning environments and outcomes as the quality indicators, while Moosa (2006) added assessment, research and communication in the list. In this regards, Her Majesty Inspectorate of Education (HMIE) identified thirty-three quality indicators for Scottish schools. However, seven were disclosed as very important for evaluation and bringing innovativeness in education, included the programmes and courses, the quality of achievement, students' need assessment and their fulfillment, students' learning experiences, students' personal and social development, curricular and vocational guidance and planning for future improvement (HMIE, 2004). Furthermore, a group of the European Commission (EC) has identified the sixteen indicators of quality of school education and keep four on the top of the list such as attainment; success and transition; monitoring of system; and resources and structures (EC, 2001). While the other group has explored the fifteen indicators of lifelong learning and keep four on the top of the list such as skills, competencies and attitudes; access and participation; resources for lifelong learning; and strategies and systems (EC, 2002).

\subsection{Quality Reforms in Teacher Education in Pakistan}

Teacher education (TE) plays a pivotal role to reform and strengthen the education system of any country. In this regards, the Federal and Provincial Governments have established, the Government Colleges for Elementary Teacher Education (GCETs/GCETE), Government Colleges of Education (GCE) and University Departments of Education (DOEs) / institutes of education and research (IER) in all provinces of Pakistan. These teacher educational 
institutions (TEIs) impart TE, training and research through various academic programmes to produce teachers, TEs and researchers to fulfill the needs and requirements of the education system of the country. There are about 135 pre-service TEIs, out of them, 114 are public sector and 21 are private sector (International Reading Association [IRA], 2008), who produce thousands of teachers every year (Government of Pakistan [GOP], 2005) and award them B.Ed, M.Ed, M.Phil/MS and Ph.D degrees in different specialization. The different academicians, educational leaders and managers, teachers, TEs and researchers have criticized the Pakistani teacher education system, its programmes and processes for its low quality. The main reasons of low quality were explored by Dilshad (2010) such as to lack of funding and resources; poorly equipped training institutions and their system; short training period; undue emphasis on quantitative expansion; narrow scope of curriculum; imbalance between general and professional courses; over-emphasis on theory as opposed to practice; lack of coordination between education departments and training institutions; deficient quality of instruction; lack of in-service training of TEs; failure in implementing for useful reforms; vague objectives; poor quality of textbooks; defective examination system; lack of supervision and accountability; and lack of research and evaluation. It was highlighted that the quality of teacher education programmes has received marginal attention through high production of teachers but sadly with low understanding of the content and methodology of the subjects (GOP, 1998). In this regards, the initiatives were taken through latest National Education Policy [NEP] (2009) to revitalize the present education system to improve the quality and connect it to the economic needs and development (GOP, 2009) through standardization, institutionalization, accreditation and certification procedures in teacher education system. For the proper implications, the accreditation council for teacher education (ACTE) has been established for the development of specific standards and requirements for teacher education programmes and institutions known as national standards for accreditation of teacher education programmes (NSATEP).

In this regards and fulfilment of objectives, the seven quality indicators have been identified for quality teacher education in Pakistan by national accreditation council for teacher education (NACTE, 2009) such as curriculum planning and design; curriculum transaction and evaluation; research, development and extension; infrastructure and learning resources; student support and progression; organisation and management; and healthy practices, which are supported the findings of Thaung (2008), Moosa (2006) and (HMIE, 2004). Whereas, the curriculum planning and design consists of goal orientation, curriculum development, programs options, academic flexibility and feedback mechanism. Curriculum transaction and evaluation consists of admission process, catering to diverse needs, teaching-learning process, teacher quality, evaluation of teaching, evaluation of learning, and examination reforms. Research, development and extension consists of promotion of research, research output, publications output, consultancy extension activities, participation in extension and linkages. Infrastructure and learning resources consists of physical facilities, maintenance of infrastructure, library as a learning resource, computers as learning resources and other facilities. Student support and progression consists of students profile, students' progression, students support and students activities. Organisation and management consists of goal orientation and decision-making. Organisational structure, powers and functions consists of perspective planning, human power, planning and recruitment, performance appraisal, staff development programmes, resources mobilization and financial management. Healthy practices consists of TQM, innovations, value-based education, social responsibilities and citizenship roles, overall development, institutional atmosphere and initiatives.

\section{Research Methods}

\subsection{Research Design}

The qualitative research approach and design was employed that revolves around epistemological and ontological (Crotty, 1998) assumptions of philosophy, supported by interpretivism and epistemological constructivism means the reality is multiple and multidimensional and the knowledge is constructed and a subjective in nature (Creswell, 2009) respectively. The list of characterizing traits was used as the criteria to judge the quality for reliability, validity and usability of the study and protocol (Sparkes \& Smith, 2009, 2014) followed by the steps suggested by Tracy (2010).

\subsection{Sample Selection}

The recruited participants $(\mathrm{n}=40)$ were selected through multiple perspectives and sampling of snowball and purposive techniques to collect the in-depth, true and real data from the TEs. As, the number of research sample may be several and ranging from 1 to 30 or 40, as to report their details properly (Creswell, 2012) and comprehensively. The recruited sample was consisted of (19 male; 21 female), six professors ( 1 male; 5 female); one associate professor (male); nineteen assistant professors ( 8 male; 11 female); and fourteen were lecturers (9 male; 5 female). The age group ranged from 28 to 58 years with an average range score 44.65 . 


\subsection{Research Protocol}

The semi-structured interview protocol was developed, piloted and upgraded before conducted on the targeted group of TEs. The investigation was done to explore the views of TEs about the factors of QE such as learners, content, processes, environment and outcomes as defined by UNICEF (2000), are acceptable worldwide. The data was collected from multiple impartial perspectives such as interviews, cross questioning during interviews, informal discussion with faculty members, observations and field notes in order to triangulate the data as this is a qualitative study that is exempted from using statistical tools (Hammersley, 2004). As triangulation of samples and their views is an important technique to extract proper data for analysis (Cohen \& Manion 2002). Identity labels (code numbers) were issued to all respondents before interviews for confidentiality (Cohen \& Manion 2002; Shaw \& Gould, 2001).

\subsection{Research Questions}

Three guiding research questions were designed to explore the answers from the narratives of TEs about quality education such as (a). What is the perception of TEs about quality in teacher education? (b). What dimensions of quality are perceived by teacher educators? (c). What activities are performed by TEs to maintain quality at their departments and institutions?

\subsection{Data Analysis}

The thematic-narrative analysis was used rigorously and comprehensively for this study to collect and analyse the data, as thematic-narrative inquiry, which is strong technique to employ as an analysis tool in the field educational studies in order to transmit the subjective experiences. As it has a capacity of capturing the correct human and personal dimensions of perception, experience and relationship between individuals and cultural context (Clandinin \& Connelly, 2000). The thematic-narrative analysis focuses on the themes and content of stories and their real meanings depending on social and cultural knowledge (Polkinghorne, 1995) to convert the said dialogues in to the real meanings through analysis (Riessman, 2008). It treats stories as a knowledge creator tool and technique that constitutes the social reality of a narrator (Etherington, 2004) of its own (Etherington, 2006, 2000; Wosket, 1999) or with other's clients (Etherington, 2007) for summative analysis (Muylaert, Júnior, Gallo, Neto \& Reis, 2014) consisting of preparation, initialization, main narration, questioning and small talk (Jovchelovich \& Bauer, 2002).

\section{Results and Discussion}

The interviews were conducted in order to listen the professional stories of TEs on the topic of research. The stories of sixteen TEs were found relevant and impressive in order to produce authentic primary data for this study in order to analyse as interviewee expressed their life experiences well with high attraction supported by authentic reasons to quote as narratives. The serial number or code to every TE (interviewee) was assigned at the place of their original names in order to keep their names confidential as per agreement, which was promised with them before conducting the interview. The important informative said narratives were recorded, selected and coded to use for the analysis of the study about their motivation and its factors.

\subsection{Perception of TEs about Quality in Teacher Education}

The perception of TEs about quality education was found quite clear and majority of them were found highly interested to work for it. The indepth perception can be found from their said statements and narratives, as the narratives of five TEs were found strongly informative, authentic and covering the description of perception and QE. As the first TE (21) said, "It is a fundamental right of every child to receive quality education". This statement is true and real in the perspectives of developed world but in developing countries, it is a dream for the inhabitants to get. Because corruption, monopoly, insincerity, dishonesty, apathy, laziness and indifference are the orders of the day. The second TE (9) said, "It is a future permanent investment for the people and next generations, which will bring the sense of duty, job opportunity, rights and responsibilities of family, neighborhood, department, city and country among them". In the light of this narrative, we can say that QE brings developments from bottom to top level among majority of the stakeholders in any country and nation, which will be the power and authority for them to known as civilized and developed nation. The third TE (5) said, "It is the most powerful tool for empowering individuals and communities to work hard for their desired and predetermined goals". This narrative clearly defined about the nations, who used their education system especially the teacher education system as the most powerful tool to empower their people and communities, who worked on the given guidelines and directions to achieve predetermined national goals, as few nations like Japanese, Chinese, Malaysians, etc. in the world. The fourth TE (34) said, "It is the only way, which improve and enhance the capacity of system to do skills development of their learners". This narrative suits the educational system of many developed countries but mostly suits two countries such as Finland and Singapore. Who did skills development of their students at all levels such as in general or normal school, vocational and university 
levels. The fifth TE (3) said, "It is a prime tool and method to bring economic growth, development and prosperity to upgrade the life standard of the people". This narrative opened all secretes of the human life and their wills and wishes, which they wanted for their country and nation.

\subsection{Dimensions of Quality Perceived by TEs}

Total eight themes or dimensions were found from the interviews data of the TEs, as they perceived at their departments, institutions and organisations.

\subsubsection{Financial and Material Resources}

Resources are available in most of the teacher education departments of the universities especially the large three universities are given new buildings. As TE (36) said, "New building has been constructed by the government in collaboration of Pre-Step project, funded by USAID. This building is fully loaded with all required facilities". Furthermore, another TE (11) said, "Newly constructed building is very much suitable to run the four years, newly designed programme". The TE (39) said, "Due to the construction of new building by USAID, the education department has been started in my university, which will promote TE in the deprived areas of Sindh". Expect of this, other teacher education departments have suitable financial and material resources developed by their universities, Federal and Provincial Governments and Canadian International Development Agency (CIDA). The buildings were designed and constructed after many meeting with faculty, students, head (s) of departments, deans and vice chancellors of the concerned universities.

\subsubsection{Qualified Teachers, Students and Staff - Student Ratios}

Teachers are selected through advertisement, testing and finally recommendations of selection boards of the universities. A TE (4) said, "I was selected out of 53 candidates. In test 09 were passed and after selection board 2 were given offer orders to join the department". Furthermore, for the appointment of lecturer in different departments of teacher education the universities required two sixteen year's degrees with different specialization, 3.00 CGPA or First Class, which is very strict type of requirement for the majority of candidates. As TE (7) said, "Two first class degrees requirement is a monopoly of the heads of the department and dean to bring their own people in to their respective departments. They advertise according the qualification of their own people from whom they got any type of financial and material benefit". While, students are selected on merit basis in most of the universities but in few departments, there are evening or self-finance programmes where the admission criteria is first come first serve with minimum requirement (second class). In this regards, a TE (26) said, "Evening programme (s) for universities and departments are the ways of income to increase the finances but it benefits the public to some extent too". No doubt, the evening programmes are supportive and beneficial for those students who work at morning time in different schools and other organisations and wanted to continue their education through evening programmes. However, the teacher-student ratio is not balanced in the teacher education departments. Teachers have much more workload to carry the classes (teaching), research activities and training (professional development) activities in their daily routines. A TE (02) said, "We have to take four courses with four credits, which is very difficult to manage in daily routines". Because, teaching is not only the responsibility of TEs but they have some more responsibilities such as preparation for lecture, counselling hours for students, assignment checking, individual feedback for constructive future results, assessment and evaluation, etc. These all problems can be solved and QE can be maintained only through keeping the balance of teacher-students ratios.

\subsubsection{Class Size, Class Contact Hours, Independent Study Hours and Total Hours}

Class size is large in large universities, which is about double and triple than small universities. As TE (20) said, "The total number of students in my class remained about 80 to 100 since last ten years of my services". However, in newly established universities the class size remained about 30 to 50, while the class contact hours remained more than large universities. As TE (31) said, "We teach four credits or hours in class, while many universities have same courses of 3 credits". The concept and counting of independent study hours is not available in majority of departments and even are not counting in the workload of students and teachers, while they work alone and check the assignments, etc. respectively. As TE (27) said, "Individual working hours are not in counting of workload, only teaching hours are counted as workload, which are total working hours of any teacher". In different developed countries like UK, USA, Australia, China, Finland, Denmark, Italy, etc. every hour is counted as workload, either is teaching, research, training and individual hour to work for the department, faculty, students, university, community and society. Especially the credits for social services, which are counted for working of the welfare of their society, counting a respectable activity in the professional life of the teachers and TEs. 


\subsubsection{Quality Teaching, Research and its Environment, Assessment and Feedback}

For quality teaching, TEs plan their lectures and activites, as TE (1) said, "For maintaining of quality we make allied materials of our subjects and power point presentations in advance and then send them to students before lectures as they prepare for coming lectures". Some TEs also use latest research papers concerned with the topic as TE (32) said, "For further understanding of students I use concerned research paper in my class for group reading, discussions and presentations". Most of the teachers do assess and discuss the copies with their students in newly established universities but the case is vice versa in large universities. A TE (30) said, "After assessing the assignments, surprise tests, essays, mid-terms and final term papers, TEs show their copies to their students and invite them to discuss about their marks and grades if they have any objection". Along with these all activities, the verbal and written feedback is also given to the students from activity to activity, assignment to assignment and time to time.

\subsubsection{Reputation, Peer Rating and Students Support}

Reputation of organisation, department and faculty plays prime role to attract students, parents and other stakeholders, which purely consists on the quality of education. In this regards, a TE (29) said, "The rules and regulations for maintaining quality education are developed and properly implemented. The marketing is done at all levels through different modes of media to increase the awareness and knowledge among public about the reputation of the university and department". Peer rating is done through different modes and by faculty and students in order to get firsthand knowledge from all concerned stakeholders to upgrade the system in order to support the students and their learning environment. As TE (37) said, "Quality Enhancement Cell (QEC) collects teacher and their pedagogy evaluation data from the students and faculty. Based on the collected data they announce the best teacher of the department, faculty and then university". Teachers and heads are requested and instructed to be most beneficial and social to their students and system. As the quality can be maintained to increase their respect for every member of the organisation.

\subsubsection{Quality Enhancement Process}

QEC is responsible for the quality enhancement process, which was established in every university of Pakistan as the regional office, connected with the central office at Learning Innovation (HEC), Islamabad. The regional or university QEC works well to collect data and announce their results but do not support teachers further to enhance their skills. As TE (40) said, "After announcement of teacher evaluation results, QEC do not meet, suggest and advice the TEs individually that what to do? In addition, How to do? They just issue the letter that your evaluation report is not good kindly improve your performance or vice versa". In this way, the quality enhancement process ends itself without drawing any fruitful results and their conclusions. Another TE (23) said, "QEC does not interview any students in order to know that what TE should improve for future endeavors as per observations of his or her students". In this way, the fault and its causes cannot be disclosed. As TE (12) said, "Nothing is suggested and arranged for TEs to support them to overcome their weaknesses". That is why TEs do not improve their selves for better future performance and results.

\subsubsection{Students' Performance, Degree Classification, Retention and Persistence}

Students performance is measure through different techniques and methods as highlighted by a TE (8) "The assignments, surprise tests, essays writing, mid-terms, presentations and final term papers are the main techniques and methods to check the performance of the students". Nowadays, four years degrees are started in teacher education, which have the worldwide recognition and are registered and recognised by HEC in Pakistan. In this regards, a TE (17) said, "The government have notified that the separate jobs would be announced for ADE and B.ED four years' degrees in educations department". This notification is done only to appreciate the candidate to get four years degree in education with some specialization as said by TE (25), "There are some specialized fields in four years education degree such as teaching of mathematics, physics, chemistry, biology, computer, economics, English, Urdu, Sindhi, Social sciences or studies, Islamic studies, special education, psychology, accounting and adult education". Due to government notifications, it is expected that the new candidates would be retented and persisted in the teacher education department as to meet the national need of teachers.

\subsubsection{Employability and Graduate Destination}

After the four years, degree graduates are eligible for different positions in education and its related departments. A TE (16) said, "As per government notifications the requirement of future jobs would be four years degree with particular specialization". This requirement and specialization would play a vital role to open job opportunities to create employability for newly graduated students, who want to be future teachers of the nation. After becoming teachers or continuing their further education towards masters and doctoral studies, they would be able to choose 
their destination. As a TE (14) said, "40 to 60 percentage graduates thinking for higher studies in their early stage studies and career as teacher". The sponsorship and funding is the main issue, which do not allow the majority of the graduates to continue their higher studies but they work hard to level their best to continue, as TE (35) said, "Many students do job at morning time and continue their higher education at evening time or weekend time and classes". To earn and meet the studies, personal and family expenses parallely individuals do jobs at morning time, which can be seen as the inspirational cases and examples available in universities of Sindh province of Pakistan, who did a great hard work and face hardships to make their life successful.

\subsection{Activities Performed by TEs to Maintain Quality at Their Departments and Institutions}

The five types of activities are performed by most of the TEs to maintain quality in their department such as planning, organizing, leading, controlling and adopting activites (Sahito \& Vaisanen, 2017b). These activites are further described and consist of making the syllabus; preparing lesson outlines and their breakdowns; preparing subject manuals; lesson planning; preparing power-point presentations; outlining the tasks; completing the material development phase; completing arrangements for conducting classes; sharing material with students; answering the questions of the students; making and sharing guidelines and instructions for assignments and other activities; finalizing the topics of essays and assignments; preparing and submitting question papers for mid and final-term exams; assessing students' tests or examinations; assigning and finalizing the grades of students after discussions with them; submitting the results of all subjects; carrying out timely counseling and guidance; giving constructive feedback on assignments and examination copies; supporting students to participate in co-curricular activities; participating actively in an efficient and effective performance-based system; acting as per the rules and regulations of the organisation; publishing research or conference papers; preparing training manuals; designing and conducting trainings; and designing, submitting and winning research funding for projects (Sahito \& Vaisanen, 2017a).

The findings of this study support the dimensions of educational quality of Steiner (1988), as he said that the essence of education and its quality depends on guided learning, which students intended to learn and teachers guide them. Education is not limited to school and schooling but it is broadest in nature to achieve concisely depending upon the content, context, process and outcomes (UNICEF, 2000). Where, the purpose of education (Steiner, 1981), authenticity of tasks (Van Merrienboer \& Kirschner, 2007) and students engagement and their success is kept under the discussion and consideration (Merrill, 2002; Frick, Chadha, Watson \& Zlatkovska, 2010). The last dimension concerned with cognition, conation and emotion. Where the cognition attempts to know the truth, its worth, uniqueness and the depth of its roots in culture, conation tries to seek the truth, goodness and its beauty; while emotion attempts to know the feeling of order, accomplishment and uniqueness of universals (Frick, 2012). The findings of the study also support the findings of Garvin (1984) as the critical dimensions of quality used as a framework for strategic analysis. The framework consists of eight dimensions such as performance, features, reliability, conformance, durability, serviceability, aesthetics and perceived quality (Garvin, 1984). Furthermore, Owlia and Aspinwall (1996) have used the findings of Garvin (1987) to interpret the quality for higher education in terms of the quality dimensions. They set it as conceptual framework, classified the dimensions of quality such as input, process, and output (IPO). Where input consists of selection of students and teachers and other entry requirements; process consists of teaching and learning, content and delivery of course unit, teachers' knowledge and expertise, accuracy of curriculum or content, concern for students, medium of instructions, social activities, assessment and evaluation; while output consists of financial rewards, placement and academic performance. Some of these dimensions are always work as mutual reinforcers and some are not. The important dimensions are those in which the TEs do implement the rules and regulations of the organisation purely depending on the practical based activities to satisfy the needs and requirements of students and other internal and external stakeholders. Because, stakeholders are real and true fans and advertisers of the products and organisations.

\section{Conclusion}

It is concluded that there are main three dimensions of quality education known as $3 P s$ such as presage, process and product dimensions. Presage dimensions consists of financial and material resources, qualified teachers and students, and staff-student ratios. Process dimensions consists of class size, class contact hours, independent study hours and total hours, quality teaching, research and its environment, assessment and feedback, reputation, peer rating and students support, and quality enhancement process; while Product dimensions consists of students' performance, degree classification, retention and persistence, employability and graduate destination. As the Finnish school education system, approaching to fulfill the demands of the increasing standards through putting a lot of trust in teachers and local education authorities in order to deliver their best to achieve the required outcomes by maintaining of decentralisation and significant accountability (Malinena, Vaisanen, \& Savolainena, 2012). Therefore, the findings 
of this study can be generalised, positively implementable and negatively avoidable differently as per needs and requirements in all areas concerned with quality. As some characteristics of Finnish teacher education are different from the other developed countries such as, it is very popular among youngsters and highly competitive (Malinena, et.al, 2012) to get in.

Quality can be managed easily in any TEDs and TEIs through the implementation of few important principles and will of management such as the transparency, equity, equality and support. However, in most of the organisations, the heads of the departments and organisation have degraded the TEs. Where the peons and guards have been deputed as spy to keep an eye on the faculty members that what is going on in their classes and offices in order to report on daily basis. This activity and condition create misunderstandings between the faculty members and the heads, which bring a great hurdle in the process of QE. On the other hand the policies of promotion, growth and development are also vague, which have been used differently for different employees depending the statement that show me the person I will show the rule to support their friends and well-wishers. The majority of documents such as minutes of meetings, rules and regulations, senate and syndicate decisions, etc. are kept secret by the management from the majority of the employees, as they cannot go for that to claim their rights, which also effect negatively on the performance of employees and the QE process. Except this, the teachers and employees unions, pressure groups and the think-tank group of management and powerful people, who always do that they want in the organisation for sake of their own and personal benefits not for the benefits of the organisation or university, institution and department, are effect negatively on the process of QE. That is why the sincerity, commitment, trustworthiness and dedication have been disappeared from the majority of the departments and organisations. The main example of the lack of these characteristics is the selection of head of departments, institution, dean of faculty and vice chancellor of any university is done on purely non-meritorious non-transparent and non-intelligent basis. However, these positions are sale out to the people who bribe and make happy the members of the committee, politicians, governor house and Secretariat and chief minster house and Secretariat. Finally, it can be said that the QE can be maintained and managed through transparent and meritorious methods and ways by selecting the competent people for the betterment of the organisation (Sahito \& Vaisanen, 2016). Where the personal benefits of any one especially the heads of departments and organisations can be not dominant than the benefits of organisation in any way and any case. Because, quality defeat the corruption and conspiracy.

\section{References}

Adams, D. (1993). Defining Educational Quality. Arlington, VA: Institute for International Research and University of Pittsburgh, USAID, Improving Educational Quality Project. http://pdf.usaid.gov/pdf_docs/Pnaca245.pdf.

Australian Quality Training Framework. (2007). Quality indicators overview. Australia. AQTF.

Barro, R. J. (1996). Determinants of Economic Growth: A Cross-country Empirical Study (Working paper 5698). National Bureau of Economic Research, Cambridge, MA.

Beeby, C. (1966). The quality of education in developing countries. Cambridge, Massachusetts: Harvard University Press. https://doi.org/10.4159/harvard.9780674188198

Benoliel, S., O'Gara, C., and Miske, S. (1999). Promoting primary education for girls in Pakistan. Arlington, Virginia: USAID's Development Experience Clearinghouse. Available at http://www.dec.org/usaid_eval.

Chande, S. U. (2006). Performance indicators of an institute of higher education. (13-20). In Proceedings of $1^{\text {st }}$ international conference on assessing quality in higher education, 11-13 December, 2006, Lahore-Pakistan.

Clandinin, D.J., \& Connelly, F.M. (2000). Narrative Inquiry: Experience and story in qualitative research. Published by Jossey-Boss, John Wiley \& Sons, Inc., San Francisco.

Cohen, L., \& L. Manion. (2002). Research Methods in Education, $4^{\text {th }}$ (ed.). Routledge, London and New York.

Creswell, J. W. (2012). Educational research: planning, conducting, and evaluating quantitative and qualitative research, $4^{\text {th }}$ (ed.). Pearson Education, Inc., Boston, USA.

Creswell, J. W. (2009). Research design: Qualitative, quantitative and mixed methods approaches, $3^{\text {rd }}$ (ed.). London, England: Sage Publications.

Crotty, M. (1998). The foundations of social research: Meaning and perspective in the research process. London, England: Sage Publications.

Dilshad, M., \& Iqbal, H. M. (2010). Quality Indicators in Teacher Education Programmes. Pakistan Journal of Social Sciences (PJSS), 30(2), 401-411. 
Etherington, K. (2000). Narrative approaches to working with adult male survivors of childhood sexual abuse. London: Jessica Kingsley.

Etherington, K. (2004). Becoming a reflexive researcher: using ourselves in research. London: Jessica Kingsley.

Etherington, K. (2006). Chicken or egg? An exploration of the relationships between physical and psychological symptoms with a woman diagnosed with Tourette's syndrome. In Counselling and Psychotherapy Research, 6(2), 138-146. https://doi.org/10.1080/14733140600711500

Etherington, K. (2007). Ethical research in reflexive relationships. Qualitative Inquiry, 13(50), 599-616. https://doi.org/10.1177/1077800407301175

European Commission. (2001). European report on quality of school education. Luxembourg: Directorate-General of Education and Culture.

European Commission. (2002). European report on quality indicators of lifelong learning. Brussels: Directorate-General of Education and Culture.

Frick, T. (2012). The theory of totally integrated education (TIE). Bloomington, IN: Monograph in Four Parts. Retrieved February 14, 2012, from http://educology.indiana.edu/Frick/TIEtheory.pdf

Frick, T., Chadha, R., Watson and Zlatkovska, E. (2010). Improving Course Evaluations to Improve Instruction and Complex Learning in Higher Education. Educational Technology Research and Development, 58(2), 115-136. https://doi.org/10.1007/s11423-009-9131-z

Garvin, D.A. (1987). Competing on the eight dimensions of quality. Harvard Business Review, 65(6), $101-109$. https://hbr.org/1987/11/competing-on-the-eight-dimensions-of-quality

Garvin, D. A. (1984). What does product quality really mean? Sloan Management Review, fall, $25-43$. http://www.oqrm.org/English/What_does_product_quality_really_means.pdf

Government of Pakistan (1998). National education policy 1998-2010. Islamabad: Ministry of Education.

Government of Pakistan (2005). National education census 2005. Islamabad: Ministry of Education. Academy of Educational Planning and Management and Statistics Division, Federal Bureau of Statistics.

Government of Pakistan (2009). National education policy 2009. Islamabad: Ministry of Education.

Greenwood, M.S., \& Gaunt, H.J. (1994). Total quality management for schools. London: Cassell

Hammersley, M. (2004). Action research: a contradiction in terms? Oxford Review of Education, 30(2), $165-181$. https://doi.org/10.1080/0305498042000215502

Her Majesty Inspectorate of Education. (2004). Quality indicators in enterprise in education. Scotland: HMIE. http://files.eric.ed.gov/fulltext/ED538125.pdf.

International Labour Organization [ILO]. (1977). Meeting Basic needs: Strategies for Eradicating Mass Poverty and Unemployment. Geneva.

International Reading Association (2008). Status of teacher education in the Asia-Pacific region. Retrieved October 14, $2009 \quad$ from http://www.reading.org/Libraries/Association_documents/Status_of_Teacher_Education_in_the_Asia-Pacific_ Region_Final.sflb.ashx

Jovchelovich, S., \& Bauer, M.W. (2002). Entrevista Narrativa. In: Bauer MW, Gaskell G. Pesquisa qualitativa com texto, imagem e som: um-manual prático. Petrópolis: Vozes; p. 90-113.

Krueger, B. A., \& Lindhahl, M. (2001). Education for growth: why and for whom? Journal of Economic Literature, 39, 1101-1136. https://doi.org/10.1257/jel.39.4.1101

Lleras-Muney, A. (2005). The Relationship between Education and Adult Mortality in the United States. The Review of Economic Studies, 72(1), 189-221. https://doi.org/10.1111/0034-6527.00329

Malinena, O.P., Vaisanen, P., \& Savolainena, H. (2012). Teacher education in Finland: A Review of a national effort for preparing teachers for the future, The Curriculum Journal, 23(4), 567-584. https://doi.org/10.1080/09585176.2012.731011

Merrill, M. D. (2002). First principles of instruction. Educational Technology Research and Development, 50(3), 43-59. https://doi.org/10.1007/BF02505024 
Moosa, K. (2006). Quality assurance in higher education: Successful approaches for improving quality in colleges and universities. (96-110). In Proceedings of $1^{\text {st }}$ international conference on assessing quality in higher education, 11-13 December, 2006, Lahore-Pakistan.

Motala, S. (2001). Quality and indicators of quality in South African education: A Critical appraisal. International Journal of Educational Development, 21, 61-78. https://doi.org/10.1016/S0738-0593(00)00014-6

Mourshed, M., Chijioke, C. \& Barber, M. (2010). How the world's most improved school systems keep getting better. London: McKinsey \& Co. Retrieved July 22, 2010, from: http://ssomckinsey.darbyfilms.com/reports/schools/How---the---Worlds---Most--Improved---School---Syste ms---Keep---Getting---Better_Download---version_Final.pdf

Muylaert, C.J., Junior, V.S., Gallo, P.R., Neto, M.L.R., \& Reis, A.O.A. (2014). Narrative interviews: An Important resource in qualitative research. Rev Esc Enferm USP, 48(2), 184-189. https://doi.org/10.1590/S0080-623420140000800027

NACTE, (2009). National standards for accreditation of teacher education program. In collaboration of HEC and Government of Pakistan.

NAAC (2007). Institutional Accreditation. Manual for Self-Study of Universities, National Assessment and Accreditation Council, Bangalore, naacindia.org/publications/Manual\%20for\%20Self\%20Study\%20for\%20Universitiesfinal-30-05-07.doc.

Owlia, M. S., Aspinwall, E. M. (1996). A framework for the dimensions of quality in higher education. Quality Assurance in Education, 4(2), 12-20. https://doi.org/10.1108/09684889610116012

Pipho, C. (2000). The sting of high-stakes testing and accountability. Phi Delta Kappan, 81(9), 645-646.

Polkinghorne, D.E. (1995). Narrative configuration in qualitative analysis. Qualitative studies in education, 8(1), 5-23. https://doi.org/10.1080/0951839950080103

Riessman, C.K. (2008). Narrative methods for the human sciences. London: Sage.

Sahito, Z. \& Vaisanen, P. (2017a). Factors Affecting Job Satisfaction of Teacher Educators: Empirical Evidence from the Universities of Sindh Province of Pakistan. Journal of Teacher Education and Educators, 6(1), 5-30. http://jtee.org/?page_id=516

Sahito, Z. \& Vaisanen, P. (2017b). The Diagonal Model of Job Satisfaction and Motivation: Extracted from the Logical Comparison of Content and Process Theories. International Journal of Higher Education, 6(3), 209-320. https://doi.org/10.5430/ijhe.v6n3p209

Sahito, Z. \& Vaisanen, P. (2016). Dimensions of Job satisfaction of Teacher Educators: A Qualitative Study of the Universities of Sindh Province of Pakistan. Journal of Curriculum and Teaching, 5(2), 43-54. https://doi.org/10.5430/jct.v5n2p43

Sallis, E. (1996). Total quality management in education. London: Kogan Page.

Shaw, I., \& Gould, N. (2001). Qualitative research in social work. London, England: Sage Publications. https://doi.org/10.4135/9781849209694

Sparkes, A.C., \& Smith, B. (2014). Qualitative research methods in sport, exercise and health from process to product. Oxford, England: Routledge. https://doi.org/10.1080/2159676X.2013.796493

Sparkes, A.C., \& Smith, B. (2009). Judging the quality of qualitative inquiry: Criteriology and relativism in action. Psychology of Sport and Exercise, 10, 491-497. https://doi.org/10.1016/j.psychsport.2009.02.006

Steiner, E. (1988). Methodology of theory building. Sydney: Educology Research Associates.

Steiner, E. (1981). Educology of the free. New York, New York: Philosophical Library.

Thaung, N.N. (2008). Quality indicator. A paper presented in the Capacity Building Workshop on Monitoring and Evaluating Progress in Education in the Pacific in Nadi, FIJI on 27-31 October 2008.

Tilak, J. B. G. (2002). Education and Poverty. Journal of Human Development, 3(2), 191-207. https://doi.org/10.1080/14649880220147301

UNESCO. (2000). The Dakar framework for action in World Education Forum, Dakar, Senegal, pp. 26-28. http://unesdoc.unesco.org/images/0012/001211/121147e.pdf. 
UNESCO (2005). EFA Global Monitoring Report Education for All, The Quality Imperative. UNESCO Publishers, New York. http://unesdoc.unesco.org/images/0013/001373/137334e.pdf.

UNICEF. (2000). Defining Quality in Education. Working Paper Series. New York: UNICEF. https://www.unicef.org/education/files/QualityEducation.PDF.

Van Merrienboer, J. J. G., Clark, R. E., \& de Croock, M. B. M. (2002). Blueprints for complex learning: The 4C/ID model. Educational Technology Research and Development, 50(2), 39-64. https://doi.org/10.1007/BF02504993

Van Merrienboer, J. J. G., \& Kirschner, P. A. (2007). Ten steps to complex learning: A systematic approach to four-component instructional design. Hillsdale, NJ: Lawrence Erlbaum Associates. https://pdfs.semanticscholar.org/8972/359c6b192ab479e81416cd725918babf4df4.pdf.

Wadsworth, H. M., Stephens, K. S., \& Godfrey, A. B. (2002). Modern methods for quality control and improvement. New York: Wiley.

Wosket, V. (1999). Therapeutic use of self: Counselling practice, research and supervision. London: Routledge. Yackulic, R. A. \& Noonan, B.W. (2001). Quality indicators for teacher training in Canada. Paper prepared for The 2001 Pan-Canadian Education Research Agenda Symposium May 22-23, 2001, Lavel University Quebec City. https://doi.org/10.4324/9780203448670 